\title{
USING TECHNOLOGY TO DETECT AND DETER ELECTRONIC CHEATING AT A LARGE PUBLIC UNIVERSITY
}

\author{
Nicholas L Ball, Utah Valley University, nicholas.ball@uvu.edu \\ Robert E Wood, Arizona State University, robert.e.wood@asu.edu \\ Gove Allen, Brigham Young University, gove@byu.edu
}

\begin{abstract}
Electronic cheating is examined in an introduction to information systems class at a large public university. We implemented a system of countermeasures to detect and deter electronic sharing of student solutions to Microsoft Excel assignments. These countermeasures include: 1) a robust set of electronic tools that immediately detect student cheating when students submit their assignments for grading; 2) a course policy that is well distributed to students, clear about the behaviors that constitute cheating, and transparent to students concerning the sanctions that will result from violations of the class policy; and 3) administrative support and application of the sanctions that are levied. The result of these countermeasures has been a significant reduction in the level of observed cheating in the class. While no system of countermeasures will detect or eliminate all cheating, the approach described in this paper has been remarkably successful.
\end{abstract}

Keywords: Cheating, Countermeasures, Electronic Assessment

\section{INTRODUCTION}

The issue of academic cheating is not new. It has likely been around as long as instructors have attempted to assess student learning. From an academic perspective, the issue of cheating has been the subject of research since at least 1904 (Barnes, 1904, pp. 481-488). Little is known about the true extent of the problem because most studies that examine student cheating rely on students to self-report the extent of their behavior (Liebler, 2016, pp. 95-101). While it is unclear what the true level of student cheating is, the self-reported numbers are not encouraging (Jones, 2011, pp. 141-150).

There are various justifications reported by students for cheating, chief among them being pressure to excel in their coursework (Gallant \& Drinan, 2006, pp. 839-860). Moreover, students seem to be unclear or at least have differences in opinion regarding what behaviors actually constitute cheating. This seems to be magnified by how the norms of different cultures influence how cheating behaviors are viewed (Jordan \& Belkin, 2016).

The problem of cheating is magnified by information technologies (Styron \& Styron, 2010, pp. 37-42). Technologies as simple as copy and paste have facilitated all forms of plagiarism, even self plagiarism. Online discussion boards have created forums for students to share even sophisticated solutions to complex problems and maintain their anonymity. The ubiquity of computing devices, such as cell phones, has made it possible to photograph and share exam questions or solutions while students are completing exams. Theses are just a few examples of how technologies have made student cheating easier and, in many cases, more difficult to detect.

Electronically administered assessments are used to reduce feedback cycles and provide other benefits to students. While being susceptible to many of the same cheating methods as traditional assessments, the benefits provided to instructors and students of electronically administered assessments make them even more vulnerable to cheating. For example, electronically administered assessments can be used to provide rapid feedback to students. If feedback is released to a student before an assignment is due, that feedback can be shared with other students to improve their performance on the same assignment. Additionally, electronically administered assessment can be used to assess learning without requiring students to complete an assessment in a particular place or at a particular time. 


\section{Issues in Information Systems \\ Volume 17, Issue IV, pp. 82-90, 2016}

Unfortunately, when students complete an assessment remotely, it can be difficult to authenticate who is actually completing the assessment (Hollister \& Berenson, 2009, pp. 271-294).

In this paper, we discuss electronic cheating in a large undergraduate information systems class at a large public university. As part of the class, students complete electronically administered and graded Microsoft Excel and Access assignments. While we don't believe that we have solved the problem of student cheating, we describe a system of technological and organizational countermeasures that have dramatically reduced the amount of observed student cheating.

\section{THE SETTING}

We examined a large introduction to information systems course at a large public university. Total course enrollment is approximately 3000 students during fall semesters and 1000 students in spring semesters. The course includes an introduction to the use of information technology in the business setting and develops technical skills in the use of spreadsheets (Microsoft Excel) and databases (Microsoft Access). The course is given in large lecture sections of about 350 students each. The course meets twice a week - one lecture each week focusing on the use of information technology, the other lecture focusing on the two technical tools, Excel and Access. Assessment is performed through weekly online quizzes, weekly assignments in either Excel or Access, and online midterm and final exams. Tutoring services are available for students to obtain help on the Excel and Access assignments. In this paper we focus on student cheating on the Excel assignments.

The Excel assignments are administered and graded electronically. Students download assignment files and complete them using the native Excel and Access applications installed on the machines they are using to complete the assignments. When students complete their assignments, they present their solutions for grading using a tool embedded in the assignment file. The grading is accomplished using code that is executed locally in macros on the student machines. Once the grading is complete, students are presented with feedback on their work and their scores are recorded in an electronic gradebook.

Electronic assessment of the Excel and Access assignments provides several benefits to the course. Feedback to the students is consistent and rapid. Within minutes, students see how they have done on any assessment. In contrast to assessments manually performed by a large group of graders, the assessments are consistent throughout the course and performed at a much lower cost. Finally the electronic assessment tools provide means of detecting when students are copying assignments wholly or in part from others. Because students are working locally with unrestricted access to files downloaded from a web site in an un-proctored environment, there is ample opportunity for copying from one another.

The course is the first required course taken in the School of Business by students majoring in business and is also taken by other students at the University either to meet specific program requirements or to partially fulfill the General Studies requirement in Mathematical Studies. In spring of 2016, 69\% of the students were business majors. The course is a prerequisite for and provides technical skills that will be required in accounting, finance and information systems courses in the college. Because this is the first course that business majors take, mitigation of cheating takes on particular importance: students immediately see the emphasis the College places on academic integrity and ethics; students who might attempt to cheat their way through college and not learn anything are instead schooled to spend time and effort in actually learning. The value of the college's degrees is enhanced as the school develops a reputation for being tough on those who do not value academic integrity.

\section{Observed Student Cheating}

With the benefits of electronic assessment comes the possibility that students will cheat. The cheating we encountered with Microsoft Excel assessments took several different forms, including a non-electronic method. This method involved two students working together on separate computers to produce two separate, but functionally identical solutions. In these cases, students would collaborate on a solution on one computer and then replicate that solution manually on a subsequent computer. While we have developed a novel approach to detecting this form of 


\section{Issues in Information Systems \\ Volume 17, Issue IV, pp. 82-90, 2016}

cheating, it requires an analysis of student behavior over a sequence of assignments. We limit the discussion in this paper to forms of electronic cheating.

We identify three prominent types of electronic cheating. The first method involves one student completing a solution to the assignment and then electronically sharing the complete solution with another student. Both students then electronically present the same solution for grading. The second method is best characterized as sharing a partial solution. In this approach, Student A opens Student B's solution file. Student A then electronically copies a portion of Student B's solution and pastes it into his file to complete his solution. The third method of electronic collaboration we encountered did not involve the sharing of partial or completed files. Instead, students provide their credentials for accessing the system to another student who downloads and completes the assignment on their behalf.

All three types of cheating have been detected in the class. We started deploying the electronic countermeasures during the fall semester of 2014. In that semester, 2815 students enrolled in the various sections of the course. Initially we were only able to reliably detect when more than one student would present the same solution for grading. The plan was to observe the level and types of cheating in fall 2014 and then start enforcing course policy in subsequent semesters once the tools were in place. During that semester, we observed that on one assignment 267, or $9.5 \%$, of the students shared solutions. It was clear that we needed to roll out the other electronic countermeasures as quickly as possible and begin taking steps to deter student cheating even during fall 2014.

\section{The Intervention}

After discovering the high levels of student cheating it was decided that an intervention would be made to deter further cheating during the fall 2014 semester. The intervention included three parts. First, a course announcement was made that there was evidence that a significant number of student files contained suspicious activity that could be interpreted as inappropriate collaboration. The announcement also clarified course policy that sanctions would be levied for cheating. Second, amnesty was offered for all cheating that was discovered to that point in the semester. Students were also offered the opportunity to have any work that was submitted for future assignments deleted if they were worried it would come under scrutiny for cheating. Finally, sanctions were levied on all students who participated in instances of cheating that were performed and detected after this announcement.

\section{Cheating Countermeasures}

We continued to develop specific countermeasures to detect and deter student cheating. These countermeasures are based on accountability theory (Lerner \& Tetlock, 1999, pp. 255-275), which states that individuals, who know that their specific actions can be attributable to them and that there will be sanctions for rule-violating behavior, will be less likely to engage in rule-violating behaviors than they would otherwise be. Our system of countermeasures includes three important and reinforcing elements. The system provides an environment characterized by: 1) technology that identifies and documents cheating behavior, 2) class policy that clearly defines both the actions that are considered cheating and the sanctions associated with violating class policy, and 3) strong administrative support.

\section{Countermeasures: Technology}

The technology used to identify and document cheating is robust and systematic. All class assignments are administered using the MyEducator content management system. Students purchase access to all of the instructional content, including assessments, for the course through the MyEducator system, which uniquely identifies each student. Students begin an assignment by logging into the MyEducator content management system and downloading an Excel assignment file (see Figure 1). 


\section{Issues in Information Systems \\ Volume 17, Issue IV, pp. 82-90, 2016}
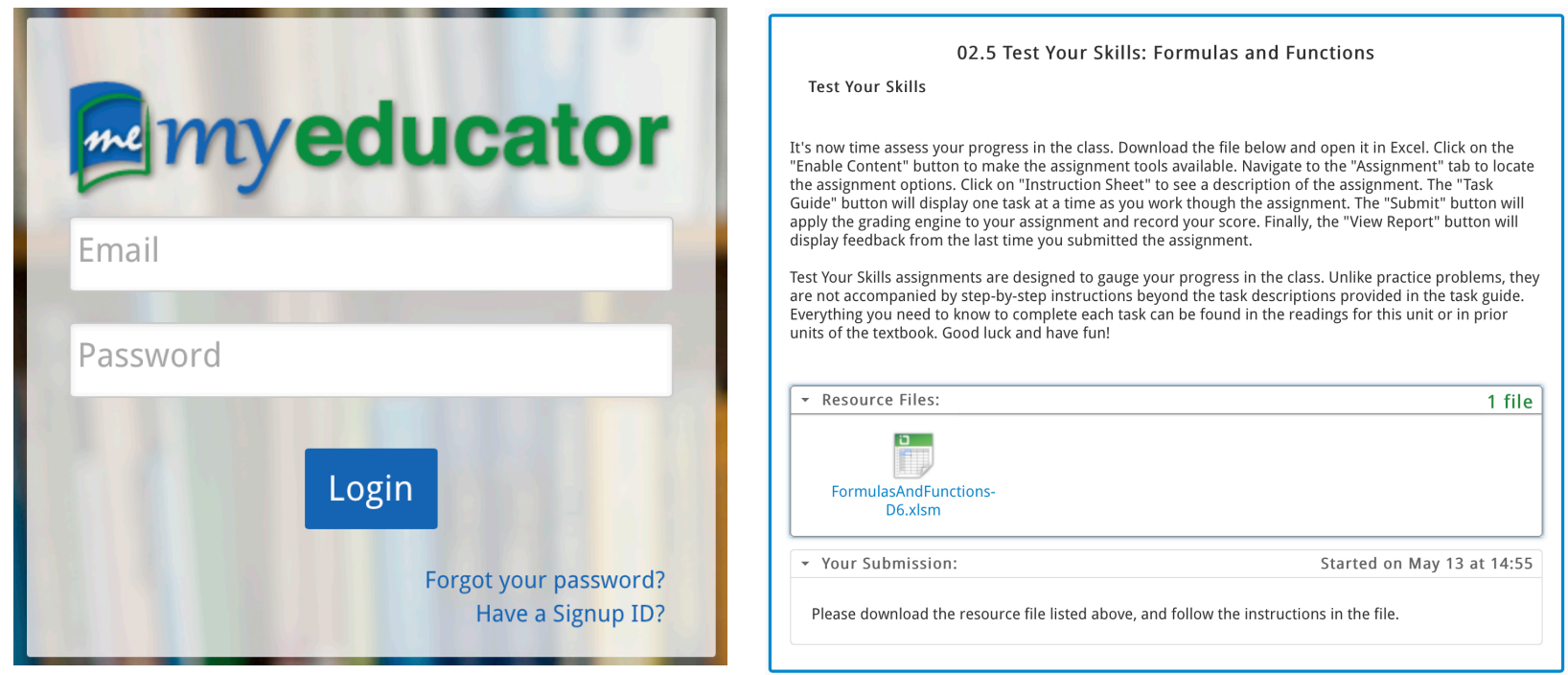

Figure 1. Student Login and File Download

At download, the system prepares a custom version of the assignment file complete with a unique identifier for each individual student embedded throughout the worksheets and cells in the file. These identifiers are not perceptible to the student, persist with the file indefinitely, and will be copied into another student's file if parts of the assignment file are electronically shared. In addition to the student's identifier, information about the computing environment used by the student when he opens the file (including computer and network configuration) are logged. Figure 2 contains a sample of the system and network information logged when the student opens an assignment file.

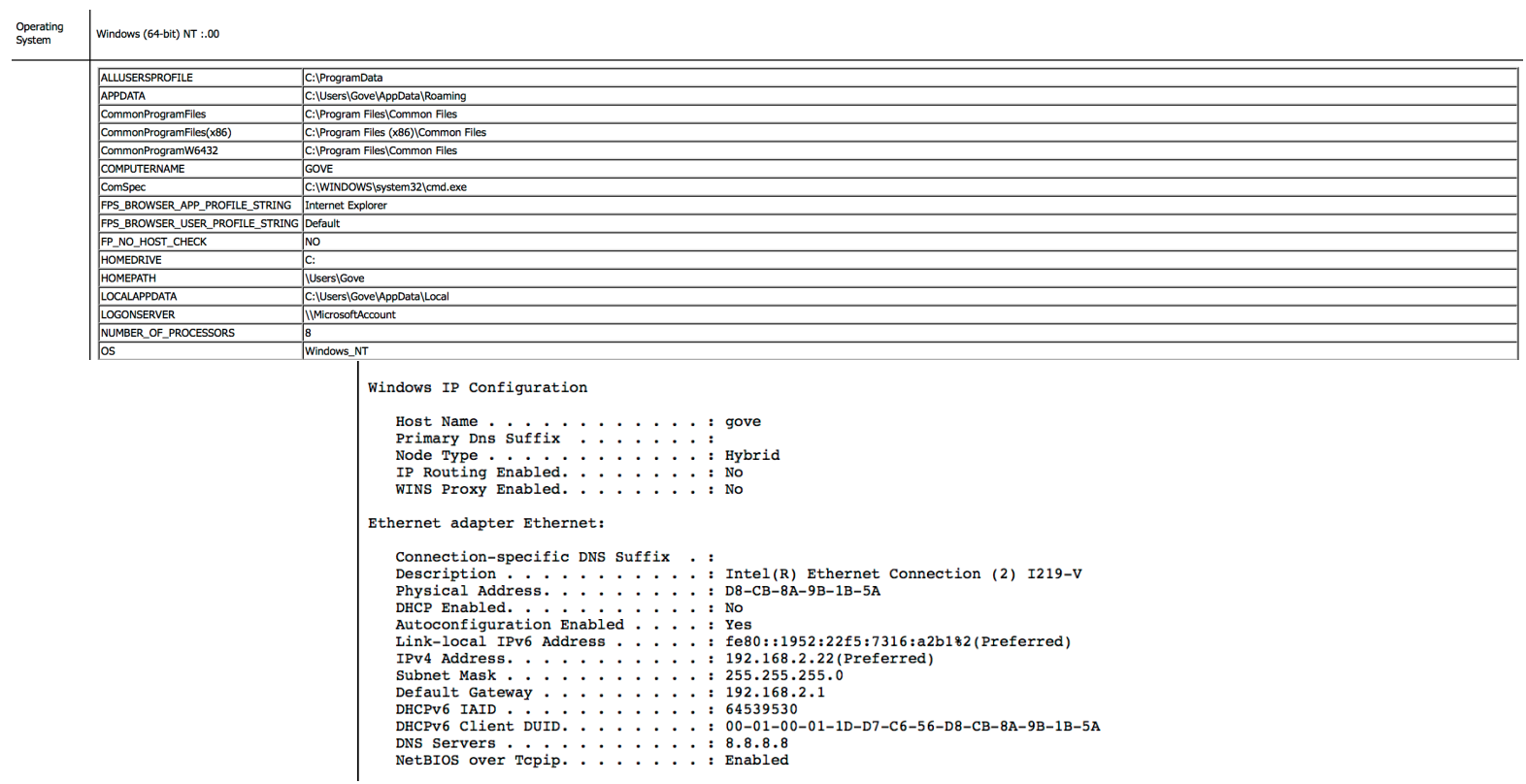

Figure 2. Example System and Network Log Information 
Students then complete the assignment using the assignment file. Students' interactions with the assignment files are appended to the $\log$. The $\log$ is stored in the assignment file. Figure 3 demonstrates example log entries that result when a student modifies a cell in the assignment file: the time of the change (down to the second), the worksheet and cell modified, the formula used to modify the cell, and the result displayed in the cell after the modification are included in the log.

\begin{tabular}{|c|c|c|c|c|c|}
\hline Time & Type & Worksheet & Address & Formula & Value \\
\hline $\begin{array}{l}2016- \\
02-01 \\
17: 27: 18\end{array}$ & $\begin{array}{l}\text { Range } \\
\text { Modification }\end{array}$ & IF Function & E18 & $=\mathrm{IF}(\mathrm{C} 18<12, \mathrm{C} 11)$ & FALSE \\
\hline $\begin{array}{l}2016- \\
02-01 \\
17: 27: 41\end{array}$ & $\begin{array}{l}\text { Range } \\
\text { Modification }\end{array}$ & IF Function & E18 & $=\mathrm{IF}(\mathrm{C} 18<12, \$ C \$ 11)$ & FALSE \\
\hline $\begin{array}{l}2016- \\
02-01 \\
17: 28: 24\end{array}$ & $\begin{array}{l}\text { Range } \\
\text { Modification }\end{array}$ & IF Function & E18 & $=\operatorname{IF}(\mathrm{C} 18<12, \$ C \$ 11, \$ C \$ 12)$ & $\$ 0.40$ \\
\hline $\begin{array}{l}2016- \\
02-01 \\
17: 28: 40\end{array}$ & $\begin{array}{l}\text { Range } \\
\text { Modification }\end{array}$ & IF Function & E19:E67 & $=\mathrm{IF}(\mathrm{C} 19<12, \$ \mathrm{C} \$ 11, \$ \mathrm{C} \$ 12)$ & $\$ 0.40$ \\
\hline
\end{tabular}

Figure 3. Log Entries for Cell Modifications

The log also includes other student interactions with the assignment (see Figure 4). These include displaying the various tasks associated with the assignment, the insertion or deletion of Excel objects (such as worksheets, charts, or PivotTables), and any grading submissions made using the students' files. Notice that all of these events are logged with the date and time that the student initiated the event.

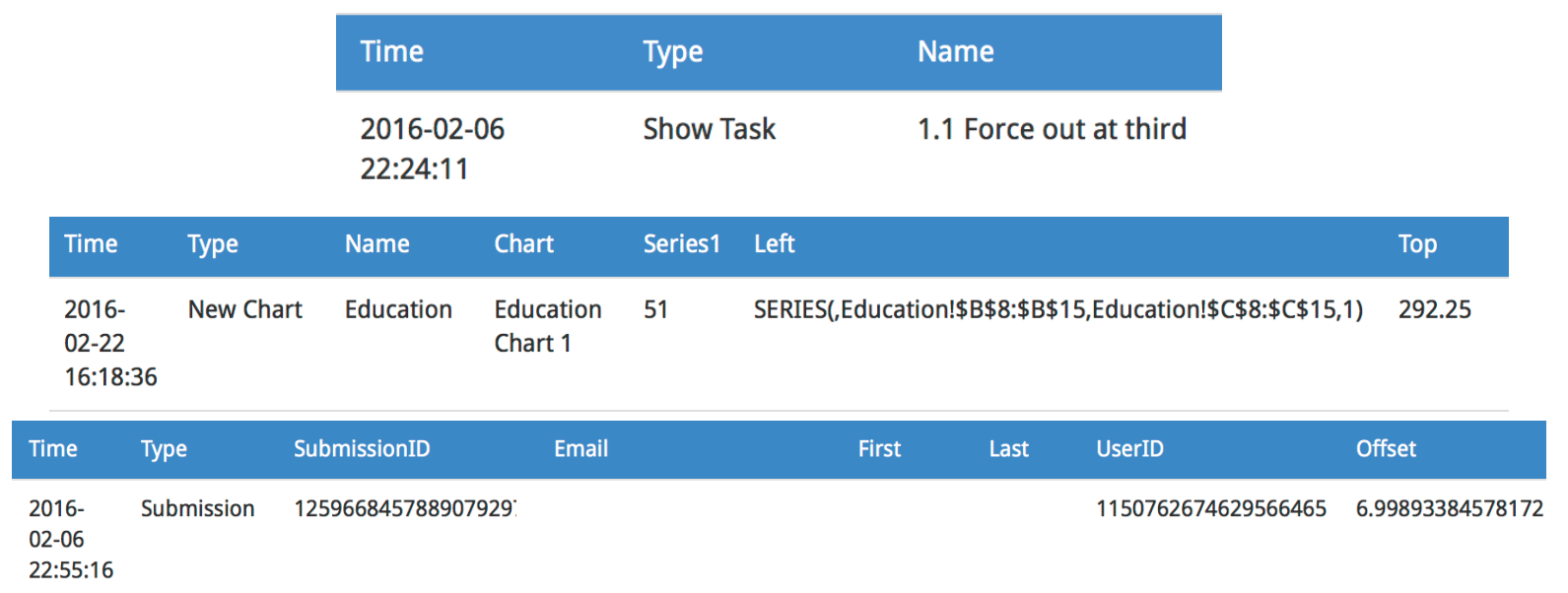

Figure 4. Example Log Entries 


\section{Issues in Information Systems \\ Volume 17, Issue IV, pp. 82-90, 2016}

The MyEducator content management system also tracks assignment information in addition to the assignment logs. This information includes: the date and time that the student downloads the assignment file, student scores for each attempt at an assignment, and the date and time at which any submission is made.

The technological countermeasures identify when student cheating has occurred. Specifically, the system identifies:

- Students who submit the same assignment file, sharing the same solution

- Students who copy parts of one solution from one assignment file to another

- Students who complete an assignment in too little time to account for completing all tasks

- Students who complete an assignment without viewing any of the tasks of an assignment

- Students who create two different, but logically identical or similar solutions, at the same time and location.

Each of the types of cheating identified is documented so that an instructor has the evidence needed to justify any sanctions administered for cheating.

\section{Countermeasures: Class Policy and Transparency to the Student}

If one is going to sanction students for cheating, one must follow a process that is viewed as transparent and fair by the students and by anyone who might later review the sanctions applied. The first requirement is to tell the students what behavior is allowed and what is not. While students are encouraged to collaborate, to work together and learn from one another, they are told that they are responsible for: (1) downloading their own assignments using their own credentials, (2) manually entering solutions to the problems, and finally (3) uploading their own assignments using their own credentials. They are warned that the software is watching to make sure there is no electronic copying and pasting of assignments or parts of assignments. They are told that the software also detects other anomalies that indicate when students are not doing their own work.

They are advised that when cheating is detected, sanctions will be applied based on the severity of the cheating and range from zero credit on the assignment up to and including expulsion from the program or college in which they are enrolled.

The other major requirement is that the cheating detection must operate in the background so that students, while working on the assignment, are not aware of the data being collected. The software must not interfere with the performance of the assignment.

It is also a good idea to have in place what might be called self-reporting amnesty, which means that if a student thinks he may have inadvertently done something wrong, he can self-report and avoid any sanctions.

\section{Countermeasures: Administrative Support}

For a system of cheating sanctions to be effective, it is absolutely required that the policies and procedures in place have the support and involvement of the administration. Professors are responsible for detecting and reporting cheating. However; the subsequent steps of imposing initial sanctions, allowing for student appeals, and deciding on the ultimate sanctions; place too much of a demand on the time of one whose primary responsibility is to teach. Moreover, having the administration handle the sanctioning process provides greater assurance that the imposition of sanctions and the determination of their severity will be consistent with college and university policies and procedures, and therefore more defensible against any challenges.

What is attractive about the electronic counter measures discussed above is that they offer concrete evidence of cheating behavior. This is quite different from the fairly subjective accusation of claiming that someone was looking at another's paper. Because the electronic evidence is so objective, administrators will tend to be supportive of this approach as long as they feel strongly about mitigating student cheating. 
FINDINGS AND DISCUSSION

The results of the countermeasures put in place to detect and deter cheating have been dramatic. There was both an immediate effect during the fall semester of 2014 and there continues to be an ongoing effect continuing to the current semester. We will present and discuss both the immediate and ongoing effects.

\section{The Immediate Effect}

Table 1 outlines instances of observed cheating. There are three time periods depicted in the table. First we list the amount of cheating in fall 2014 before the intervention in the class. We then outline the amount of cheating in the fall 2014 class after the intervention. Finally, we depict the amount of cheating in a subsequent semester, fall 2015.

In fall 2014 before the intervention in the class, we observed 267 of the 2815 students enrolled in the fall 2014 class shared solutions for a single assignment. This represented $9.5 \%$ of the students in the class. It should be noted that only one of the electronic tools we developed to detect cheating was online at that point in the semester. We were unable to detect students who shared a partial solution or who provided their credentials to another student to complete their work. The overall level of cheating prior to the intervention in fall 2014 was likely higher than the $9.5 \%$ we observed.

The immediate effect of the intervention is demonstrated by the amount of cheating after the intervention. As mentioned earlier, the tools for detecting cheating were being rolled out during the fall 2014 semester. They were not completely implemented until students were completing assignments 7 and 8 in the class. Of the 2815 students enrolled in the class, $42(1.5 \%)$ shared a submission on assignment 7 and $20(0.7 \%)$ shared a solution on assignment 8 . We also observed that 8 students shared a partial solution on assignment $7(0.3 \%)$ and no students shared a partial solution on assignment 8 . This represents a dramatic reduction in the amount of cheating immediately after the intervention.

In addition to the observed changes in the level of student cheating, there is anecdotal evidence that student behavior has changed. News of student sanctions was even discussed in an online student forum. As word of student sanctions passed from student to student, student belief that sanctions would result from cheating behavior was strengthened.

Table 1. Frequency of Observed Cheating Behaviors

\begin{tabular}{|l|l|l|l|}
\hline \multicolumn{1}{|c|}{ Cheating Behavior } & $\begin{array}{c}\text { Fall 2014 } \\
\text { Pre-Intervention }\end{array}$ & $\begin{array}{c}\text { Fall 2014 } \\
\text { Post-Intervention }\end{array}$ & \multicolumn{1}{c|}{ Fall 2015 } \\
\hline Sharing full solution & A4: $267 / 2815(9.5 \%)$ & A7: $42 / 2815(1.5 \%)$ & A1: $7 / 2734(0.3 \%)$ \\
& & A8: $20 / 2815(0.7 \%)$ & A2: $9 / 2734(0.3 \%)$ \\
& & & A3: $11 / 2734(0.4 \%)$ \\
& & & A4: $2 / 2734(0.1 \%)$ \\
& & & A5: $2 / 2734(0.1 \%)$ \\
& & & A6: $10 / 2734(0.4 \%)$ \\
Sharing partial solution & Tools unavailable & A7: $8 / 2815(0.3 \%)$ & A $10 / 2734(0.4 \%)$ \\
& & A8: $0 / 2815(0.0 \%)$ & A2: $0 / 2734(0.04 \%)$ \\
& & & A3: $4 / 2734(0.1 \%)$ \\
& & & A4: $3 / 2734(0.2 \%)$ \\
& & & A5: $0 / 2734(0.0 \%)$ \\
& & & A6: $0 / 2734(0.0 \%)$ \\
& & & A7: $6 / 2734(0.2 \%)$ \\
& & & A8: $0 / 2734(0.0 \%)$ \\
\hline
\end{tabular}


There were some repeat offenders in the fall 2014 class, however the total number of repeat offenders is also relatively small. The number of students who shared solutions for assignment 4 and assignment 7 was $16(0.6 \%)$. Ten students $(0.4 \%)$ shared solutions for assignment 4 and assignment 8 . The number of students who shared solutions for assignments 7 and 8 was $13(0.5 \%)$. Finally, $7(0.3 \%)$ students shared solutions on all 4 assignments.

Table 2. Frequency of Repeated Cheating Behaviors Fall 2014

\begin{tabular}{|l|c|}
\hline Assignment Combination & $\begin{array}{c}\text { Number of Repeat } \\
\text { Offenders }\end{array}$ \\
\hline A4 \& A7 & $16(0.6 \%)$ \\
\hline A4 \& A8 & $10(0.4 \%)$ \\
\hline A7 \& A8 & $13(0.5 \%)$ \\
\hline A4, A7, \& A8 & $7(0.3 \%)$ \\
\hline
\end{tabular}

We attribute the fact that there were relatively few repeat offenders to the speed with which offenders were sanctioned. Cheating behavior is identified as soon as students submit their work, so sanctions can be levied as soon as possible after the behavior is identified. This has a normative effect on students, who appear to change behavior after the first (and less severe) sanctions.

We acknowledge that students also make attempts to cheat in novel and more exotic ways. For example, in fall 2014, we discovered a group of 35 students who shared their solution to assignment 4 and then attempted to cheat in a much more sophisticated fashion after the mid-course intervention. An enterprising student used the login credentials for the other students to download the unique assignment files for each student. He then recorded a macro of himself creating an assignment solution. Finally, he applied this macro to all of the other students' assignment files. While this method was detected, it does raise the concern that it likely is impossible to detect all forms of cheating.

\section{Ongoing Countermeasures}

The level of cheating detected post intervention provides strong support for the efficacy of the countermeasures. When the countermeasures were in place for a complete semester in fall 2015 , we found similar promising results (see Table 1). Here the assignment with the highest level of solution sharing was assignment 3 , where 11 out of the $2734(0.4 \%)$ students enrolled in the class shared a solution. Assignment 7 had 6 of the 2734 students $(0.2 \%)$ share a partial solution. The observed levels of cheating are far lower than what was observed on assignment 4 during fall 2014.

There also appear to be fewer repeat offenders in fall 2015 (see Table 3). In total 38 students were observed cheating on at least one assignment. Of these 38 students, only 10 cheated on a second assignment. Only one student cheated on a third assignment. Again, since cheating behavior is detected when students submit their work, and sanctions are levied quickly; those students who choose to cheat on an assignment are less likely to cheat on a subsequent assignment.

Table 3. Level of Repeated Cheating Observed during Fall 2015

\begin{tabular}{|c|c|}
\hline $\begin{array}{c}\text { Number of } \\
\text { Offenses }\end{array}$ & $\begin{array}{c}\text { Number of } \\
\text { Students }\end{array}$ \\
\hline 1 & 38 \\
\hline 2 & 10 \\
\hline 3 & 1 \\
\hline 4 & 0 \\
\hline 5 & 0 \\
\hline 6 & 0 \\
\hline 7 & 0 \\
\hline 8 & 0 \\
\hline
\end{tabular}




\section{Issues in Information Systems \\ Volume 17, Issue IV, pp. 82-90, 2016}

\section{CONCLUSIONS}

In this paper, we have discussed how electronic cheating has been detected and mitigated in an introduction to information systems class at a large public university. We implemented a system of countermeasures to detect and deter electronic sharing of student solutions to Microsoft Excel assignments. These countermeasures include: 1) a robust set of electronic tools that immediately detects student cheating when students submit their assignments for grading; 2) a course policy that is well distributed to students, clear about the behaviors that constitute cheating, and transparent to students concerning the sanctions that will result from violations of the class policy; 3 ) administrative support and application of the sanctions that are levied.

The result of these countermeasures has been a significant reduction in the level of observed cheating in the class. When the electronic detection tools first went online, nearly $10 \%$ of students were observed sharing solutions to assignments. Once the system of countermeasures was fully implemented, the level of cheating was reduced to less than $1 \%$. While no system of countermeasures will detect or eliminate all cheating, the system described in this case study has been remarkably successful.

\section{REFERENCES}

Barnes, E. (1904). Student Honor: A Study in Cheating. International Journal of Ethics, 14(4), 481-488.

Gallant, T. B., \& Drinan, P. (2006). Organizational Theory and Student Cheating: Explanation, Responses, and Strategies. The Journal of Higher Education, 7 (5), 839-860.

Hollister, K. K., \& Berenson, M. L. (2009). Proctored Versus Unproctored Online Exams: Studying the Impact of Exam Environment on Student Performance. Decision Sciences Journal of Innovative Education, 7(1), 271-294.

Jones, D. L. (2011). Academic Dishonesty: Are More Students Cheating? Business Communication Quarterly, 74 (2), 141-150.

Jordan, M., \& Belkin, D. (2016, June 5). Foreign Students Seen Cheating More Than Domestic Ones. The Wall Street Journal.

Lerner, J. S., \& Tetlock, P. E. (1999). Accounting for the effects of accountability. Psychological Bulletin, 125(2), 255-275.

Liebler, R. (2016). Collecting and Reporting Self-Reports of the Number of Times Cheated. College Student Journal, 50(1), 95-101.

Styron, J., \& Styron, R. A. (2010). Student Cheating And Alternative Web-Based Assessment. Journal of College Teaching \& Learning, 7(5), 37-42. 